\title{
Marrying Exploratory Modelling to Strategic Planning: Towards Participatory Model Use
}

\author{
$\underline{\text { S. Malekpour }}{ }^{\mathrm{a}}$ F.J. de Haan ${ }^{\mathrm{a}}$ and R.R. Brown ${ }^{\mathrm{a}}$ \\ ${ }^{a}$ Monash Water for Liveability, Monash University, Australia \\ Email: shirin.malekpour@monash.edu
}

\begin{abstract}
Long-term strategic planning in the context of urban systems involves uncertainties beyond mere error margins on assumptions and predictions. Exploratory modelling, as opposed to the wellestablished predictive/deterministic modelling, has emerged to cope with, rather than reduce, uncertainty in this realm. However, the scholarly commentary is largely silent, despite its advocacy, on how this type of modelling is integrated into a participatory strategic planning context. In particular, these models are often regarded as tools to support planning; but the process methodologies for model use in a participatory setting are not well- developed. To form the underpinnings of such a methodology, this paper puts forward a theoretical rationale that justifies how exploratory modelling techniques may contribute to fulfilment of participatory strategic planning objectives. To do so, the main objectives of strategic planning in the public sector are extracted from the literature and outlined. Then an overview of the social scenario modelling literature, mainly involving exploratory modelling, is presented and the main features of this type of modelling are derived. It is then discussed that a critical element that hinders the fulfilment of strategic planning objectives, as highlighted in literature, is the cognitive limitations of planners and decision makers to process and to use information and their over-reliance on limited experience to anticipate the future. The pitfalls resulting from such human limitations include frame-blindness, cognitive biases and false attributions of causality. According to the theoretical rationale developed in this paper, exploratory modelling brings a portfolio of possible futures and strategy outcomes, which are normally beyond direct experience, to a perceivable sphere for planners and decision makers. Therefore, a virtual experience of possible future realities will be created. This may challenge the mental frames of the planners, reduce cognitive biases in scenario planning and facilitate following long and dynamic sequences of causes and effects. The result might be pre-maturation of the participants' perception about future issues and strategy outcomes. Consequently, fulfilment of strategic planning objectives in practice would be more likely. This rationale underpins the research agenda for development of a currently absent process methodology that incorporates exploratory modelling approaches within a participatory strategic planning context. This methodology shall aim to strengthen the perceptions' maturation process and circumvent the aforementioned pitfalls. The ingredients of such a process methodology may include but are not necessarily limited to: using scenarios for visioning and arriving at shared perspectives, facilitating strategy experiments and performing robustness analyses across various strategies.
\end{abstract}

Keywords: $\quad$ Exploratory modelling, strategic planning, participatory, public sector, uncertainty 


\section{INTRODUCTION}

Delivery of public infrastructure across industrialised countries has been underpinned by a traditional sociotechnical paradigm that assumed predictability of the future and defined effective and affordable service provision as its sole objective (Dominguez et al. 2011; Störmer et al. 2009). Along the same line, Operations Research initially dealt with single objectives and limited variables in context conditions (Walker 2000). However, in the face of the increased uncertainty in context conditions (Dominguez et al. 2011; Walker 2000), such as rapid urbanisation, and the ongoing debate on the multiple, sometimes contradicting, objectives of public services (Henderson \& Schilling 1985; United Nations 2004), long-term planning in the public sector could no longer fit into the traditional paradigm. Strategic planning evolved from operations research to deal with these uncertain and complex conditions.

Scenario planning emerged as a tool for strategic planning (Varum \& Melo 2010; Schoemaker 1993). The first generation of scenarios was developed to respond to the question of "What will happen?". These predictive scenarios (Börjeson et al. 2006) aim at forecasting the future, using hard quantitative techniques such as trend extrapolation, growth models, etc. (Sondeijker 2009). The second generation of scenarios respond to the question of What can happen? They are explorative scenarios (Börjeson et al. 2006) that go beyond estimating probability distributions and aim at producing a possibility space of the future. They emerged following the recognition that for some systems, e.g. social systems, the future cannot be extrapolated from the past trends (Sondeijker 2009) and that predictive approaches cannot withstand under the conditions of deep uncertainty where the system models and the input parameters into the models are not known (for a detailed description of deep uncertainty see Lempert et al. 2003).

In the recent decades computational methods and computer modelling has become associated with almost every sort of policy concern (Bankes 1993), including scenario planning. Predictive modelling, which is appropriate for closed systems with manageable uncertainties, results in a single future scenario for given conditions (Bankes et al. 2002). On the other hand, for systems with open boundaries under deep uncertainty, exploratory modelling has been introduced (Bankes 1993) as an alternative, delivering a portfolio of possible futures. In one of the pioneering attempts to develop exploratory modelling, Bankes (1993) stated that due to high degree of complexity and deep uncertainty in the systems for which no model could be validated experimentally, no discipline would be better benefited from exploratory modelling than operations research and the policy sciences (Bankes 1993).

More than two decades later, while public organizations need to cope with increased uncertainty and complexity in the strategic planning process, the use of models as scenario tools has remained an exception rather than a common practice (Andersson et al. 2008). Exploratory foresight approaches, which could cope with the question of what can happen, are not yet well-developed in the context of strategic planning (Störmer et al. 2009). In other words, whereas the public sector needs support to undertake the strategic planning process and exploratory scenario modelling techniques are claimed to be supportive for that, the two have not yet been coupled. This might be attributed to the lack of a process methodology for effective operationalization of exploratory modelling techniques within a participatory strategic planning context. The scholarly commentary, despite its advocacy, has been largely silent on how this type of modelling could be integrated into a participatory planning setting.

To form the underpinnings of such a methodology, this paper puts forward a theoretical rationale that justifies how the features of exploratory modelling techniques may contribute to fulfilment of strategic planning objectives. Section 2 presents an overview of the public sector strategic planning literature and extracts the main objectives that are highlighted in this literature. Section 3 presents an overview of the social scenario modelling literature and extracts the main features of such techniques as emphasised in the relevant literature. Section 4 argues how the features of social scenario modelling mentioned in section 3 may contribute to fulfilment of the strategic planning objectives as outlined in section 2 .

\section{STRATEGIC PLANNING IN THE PUBLIC SECTOR: THE OBJECTIVES}


Strategic planning was initially developed as a goal-oriented approach that used various techniques (e.g. scenario planning) to seek efficiency. However, within the discourse of the scholarly community, strategic planning has expanded from a goal-oriented procedure to a process-oriented way of thinking, acting and learning (e.g. Bryson et al. 2009; Tonn et al. 2000; Albrechts 2012; Pahl-Wostl \& Hare 2004; Bryson 2004). Under the new strategic planning paradigm, the process of planning is as important as the artefact that it produces, i.e. the strategic plan. Within this orientation, collaborative (participatory) planning has received widespread attention, as a way to build resilience towards uncertainties in highly complex issues where values and objectives are diverse (Tonn et al. 2000). In the public sector, participatory strategic planning was also a response to the increased demand for the involvement of civil society in the public sector decision making (United Nations 2004) to bring legitimacy to the planning process (Silver et al. 2002).

Nowadays, the differentiation between the outcome-oriented domain of strategic planning literature and the process-oriented domain is disappearing as they overlap in many of their objectives and functions. For instance, the function of scenario planning, primarily a part of the outcome-oriented domain, goes beyond simply generating results, to creating integration among different (sometimes conflicting) viewpoints about the future (Wiek et al. 2006). This study brings together some of the literature that builds upon the outcomeoriented as well as some that builds upon the process-oriented notion of strategic decision making, and outlines the agenda of a participatory strategic planning process (see Figure 1) as:

- $\quad$ producing robust strategies in the face of uncertainty and complexity (e.g. Lempert et al. 2003; Walker 2000; Schoemaker 1993)

- sharing a common vision and understanding of the future (e.g. Albrechts 2012; Dominguez et al. 2011)

- facilitating uniform translation of the produced strategies (e.g. Czarniawska 2012)

- legitimising the planning process and building trust (e.g. Silver et al. 2002; Beierle \& Konisky 2000)

- improving coordination and reducing conflict throughout the process and after implementation (e.g. Beierle \& Konisky 2000; Wheeland 2003; Albrechts 2012).

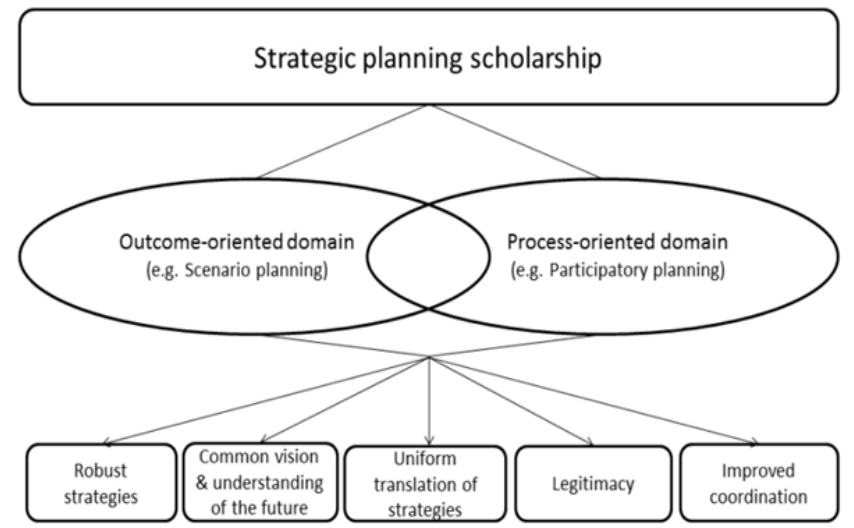

Figure 1: Strategic planning orientations and main objectives

\section{SOCIAL SCENARIO MODELLING: THE FEATURES}

The modelling literature on social scenarios is studied in this paper under two domains; 1): exploratory modelling, where the focus is on the model and on producing an ensemble of possibilities, and 2): participatory modelling, where the focus is on the modelling environment.

The main features of exploratory modelling as highlighted in the literature may be outlined as (see Figure 2):

- testing the implications of what is known and the consequences of what is uncertain (Bankes 1993)

- $\quad$ pursuing long chains of inference through utilization of fast processing power and virtually unlimited memory of computers (Lempert et al. 2003; Bankes et al. 2002)

- facilitating navigation through the space of the plausible by delivering a large ensemble of futures states (Bankes 1993). 
Participatory modelling, which focuses on the modelling environment rather than the model itself, has developed under the rationale that management of complex systems can be better dealt with through involving various or even contradicting views on an issue (Jones et al. 2009).

The main features of participatory modelling outlined in the literature include (see also Figure 2):

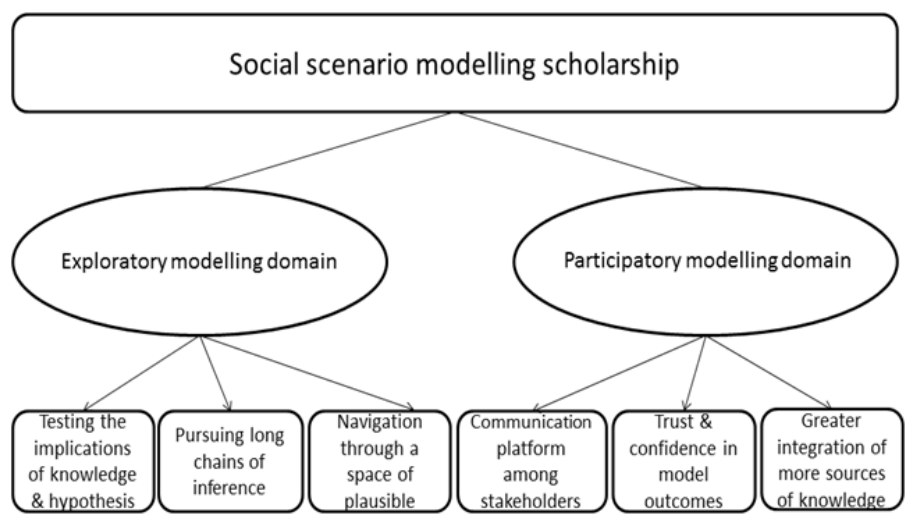

- providing a communication platform among the stakeholders

Figure 2: Social scenario modelling orientations and main features with diverse and conflicting views (e.g. Andersson et al. 2008; Jones et al. 2009)

- legitimating the modelling process through building trust and confidence in the participants with regard to model inputs and outcomes (e.g. Andersson et al. 2008; Jones et al. 2009)

- integration of more sources of knowledge into the modelling process and therefore improving the problem solving capacity of the models (e.g. Jones et al. 2009; Hare et al. 2003).

\section{THEORETICAL RATIONALE FOR COUPLING STRATEGIC PLANNING AND EXPLORATORY MODELLING TECHNIQUES IN A PARTICIPATORY SETTING}

\subsection{Why does strategic planning need support to fulfil its objectives?}

Although strategic planning aims at the objectives outlined in Figure 1 and can move towards their fulfilment, there is no guarantee that it will (Bryson 2004). To fulfil the objectives of strategic planning ideally, one needs to understand and monitor the social or socio-technical issues from their emergence to evolution. There is also a need to anticipate the future state of the issues. A critical element in this regard, however, is the cognitive limitations and the confined capability of planners and decision makers to process and to use information (James \& Barnes 1984; Schwenk 1984; Schoemaker 1993). Humans are not well capable of understanding, caring about and acting purposefully upon phenomena that occur beyond their direct experience (Gobster et al. 2007). Wright \& Goodwin (2009) outline three pitfalls resulting from human limitations that lead to low predictability in planning and decision making. They include: 1) inappropriate framing, 2) cognitive biases and 3) inappropriate attributions of causality.

Inappropriate framing refers to the planners and decision makers being captured within narrow frames of reference or frames that are embedded in the past. In this case strategic failure could result from a crisis of perception, i.e. the inability to observe an emergent reality due to being locked in obsolete mental frames (Wright \& Goodwin 2009).

Cognitive biases result from the use of heuristics in decision making (Tversky \& Kahneman 1974). Tversky \& Kahneman (1974) showed that when faced with complex and uncertain decision situations, people often rely on a limited number of heuristics that reduce the complicated assessment and forecasting task to simple judgemental operations. These heuristics, although sometimes useful, may lead to severe and systematic errors (Tversky \& Kahneman 1974). Since a strategic decision is a special kind of complex decision under uncertainty (Schwenk 1984), strategic planners will not be exempted from the aforementioned pitfall either.

Inappropriate attributions of causality results from over-reliance on limited experience and confined human ability to follow long chains of causes and effects when complex interactions exist among diverse parameters (Wright \& Goodwin 2009).

\subsection{How can exploratory modelling techniques support strategic planning?}


The features of exploratory modelling (Figure 2) may have the potential to deal with the limitations mentioned in the previous section, if coupled with the strategic planning process. Exploratory models can bring a portfolio of possible futures and strategy outcomes into a perceivable sphere for strategic planners. 'Perceivable sphere', in this context, refers to the domain in which humans could perceive a phenomenon and interact with it. The virtual experience of possible futures, which are normally beyond direct experience, might help the planners to better understand, care about and act purposefully upon them.

Testing the implications of knowledge and hypotheses using computer models that produce a portfolio of outputs, rather than human narratives and intuitive logic methods that produce a few outputs, is likely to challenge the mental frames of the planners. In this way humans' vulnerability to ignoring an emergent reality is likely to improve.

Pursuing long chains of inference using computers, another feature of exploratory modelling, can facilitate combining diverse facts to reveal their implications for the future. The limited human ability to follow the long and dynamic sequences of causal impacts can be supported using the processing power and the memory capacity of computers.

Navigation through a large ensemble of future realities, another feature of exploratory modelling, may also assist the planners to break through their mental frames.

The use of exploratory models is also likely to reduce the use of heuristics and subjective judgments in scenario planning. This may contribute to the reduction of cognitive biases in the planning process. Since subjective judgments and cognitive biases are a strong source of distrust and conflict in the planning process (Barnes, 1984), their minimisation may directly translate to improved legitimacy and improved coordination, as targeted in strategic

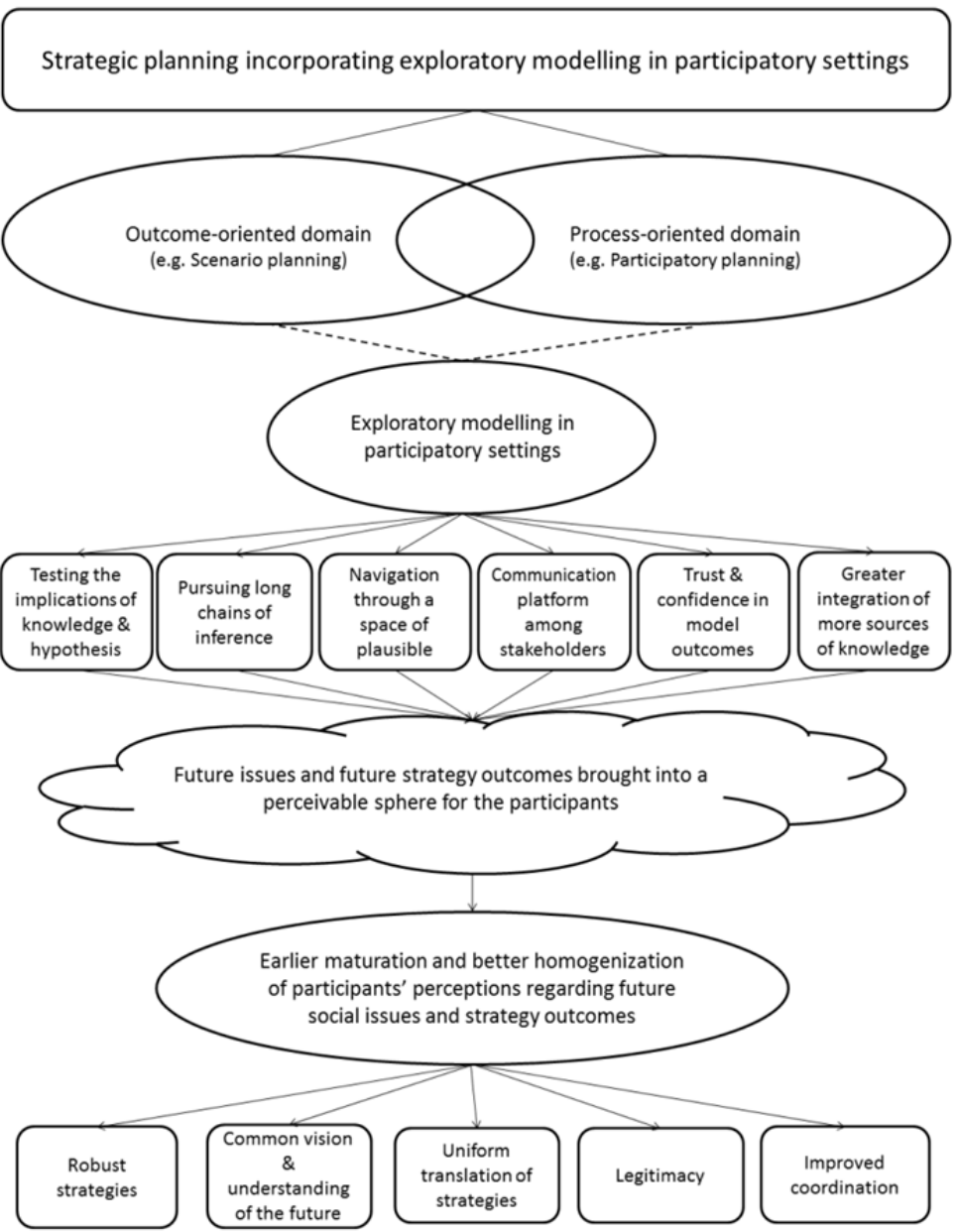

Figure 3: The rationale that explains the potential contributions of exploratory modelling techniques to fulfilment of strategic planning objectives in a participatory context in the public sector planning.

The integrated outcome of the processes mentioned above (i.e. challenging the mental frames of the planners, following long and dynamic sequences of causality and reducing cognitive biases), could facilitate the maturation of the planners' perceptions with respect to future social issues and strategy outcomes. Social issue maturation is defined by McGrail et al. (2013) as the evolution of issue awareness and ownership from individual interest concerns (e.g. early concerns for environmental health) to general public management (e.g. national sustainability programs). Building on this notion, it can be hypothesised that bringing the social issues to a perceivable sphere is likely to fast track their maturation process within the planners' perception. This may facilitate the construction of more robust strategies against future issues, which is an explicit objective of strategic planning. 
If the whole processes occur within a participatory setting, where the expertise and the experience of a larger group are brought together, the result is likely to be an integrated and inclusive perception of future issues and strategy outcomes. This could facilitate the construction of common vision and understanding of future, plus uniform translation of strategies, as the other two objectives of strategic planning. Figure 3 depicts schematically the rationale that explains the potential contribution of exploratory scenario modelling techniques to fulfilment of strategic planning objectives in the public sector.

\section{DISCUSSION AND CONCLUSIONS}

This study has put forward a theoretical rationale that justifies how exploratory scenario modelling tools may contribute to fulfilment of strategic planning objectives in the public sector. According to this rationale, exploratory model use as a part of the participatory strategic planning process is more than drawing a portfolio of possible futures and performing policy testing. It is a virtual experience of future realities and a learning and negotiation process that is likely to challenge the mental frames of the participants, reduce cognitive biases and enable following sequences of causal impacts. This does not imply that subjective judgments, biases or vested interests will be completely eliminated from the planning process. But exploratory modelling techniques may enable reflexivity and maturation of participants' perception with regard to future issues and therefore result in making more informed decisions and judgements.

This rationale underpins the research agenda for the development of a currently lacking process methodology to operationalise exploratory scenario modelling approaches within a participatory strategic planning setting. This methodology shall aim to enable virtual reflexivity and issue maturation using the interface of the exploratory modelling techniques with the participatory context. This could circumvent the pitfalls that result from humans' cognitive limitations to process and to use information. The ingredients of such a methodology would include but are not necessarily limited to: using scenarios for visioning and arriving at shared perspectives, facilitating computer-assisted thought and strategy experiments and performing robustness analyses across various strategies. Figure 4 maps out some of the components of such a process methodology as mentioned above.

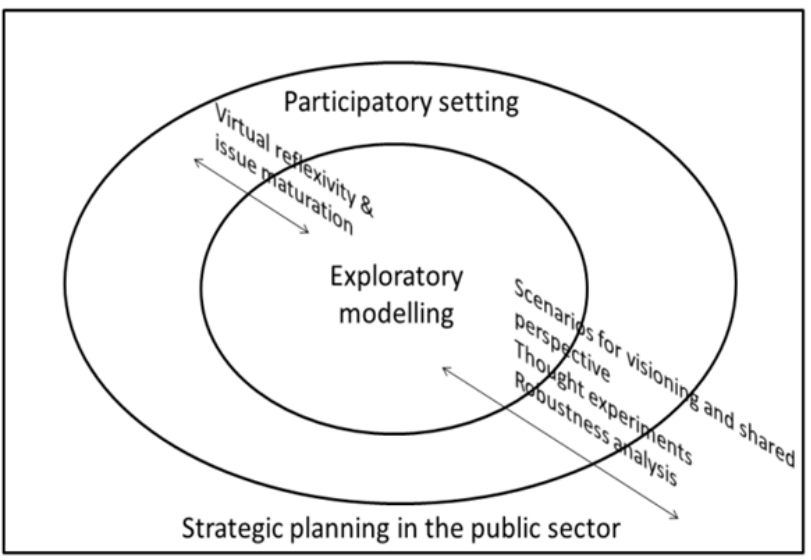

Figure 4: Map of some of the components of the research agenda aimed at incorporating exploratory modelling approaches in a participatory strategic planning context

\section{ACKNOWLEDGMENT}

This research is funded under the Australian Research Council's Linkage Projects Scheme (project number LP120100683) for which Dr de Haan is the recipient of an Australian Research Council Post-doctoral Fellowship Industry (APDI).

\section{REFERENCES}

Albrechts, L. (2012). Reframing strategic spatial planning by using a coproduction perspective. Planning Theory, 12(1), 46-63.

Andersson, L., Jonsson A., Wilk, J. and Alkan Olsson, J. (2008). Use of participatory scenario modelling as platforms in stakeholder dialogues. Water SA, 34(4), 439-447.

Bankes, S., Lempert, R. and Popper, S. (2002). Making Computational Social Science Effective: Epistemology, Methodology, and Technology. Social Science Computer Review, 20(4), 377-388.

Bankes, S. (1993). Exploratory Modeling for Policy Analysis. Operations Research, 31(3), 435-449. 
Beierle, T.C. and Konisky, D.M. (2000). Values, conflict, and trust in participatory environmental planning. Journal of Policy Analysis and Management, 19(4), 587-602.

Börjeson, L., Höjer, M., Dreborg, K.-H., Ekvall, T. and Finnveden, G. (2006). Scenario types and techniques: Towards a user's guide. Futures, 38(7), 723-739.

Bryson, J.M. (2004). Strategic Planning for Public and Nonprofit Organizations 3rd ed., San Francisco: John Wiley \& Sons, Inc.

Bryson, J.M., Crosby, B.C. and Bryson, J.K. (2009). Understanding Strategic Planning and the Formulation and Implementation of Strategic Plans as a Way of Knowing: The Contributions of Actor-Network Theory. International Public Management Journal, 12(2), 172-207.

Czarniawska, B. (2012). Does Planning Belong to the Politics of the Past? Contemporary Economics, 6(4), 36-48.

Dominguez, D., Truffer, B. and Gujer, W. (2011). Tackling uncertainties in infrastructure sectors through strategic planning: the contribution of discursive approaches in the urban water sector. Water Policy, 13(3), 299-316.

Gobster, P.H., Nassauer, J.I., Daniel, T.C. and Fry, G. (2007). The shared landscape: what does aesthetics have to do with ecology? Landscape Ecology, 22(7), 959-972.

Hare, M., Letcher, R.A. and Jakeman, A.J. (2003). Participatory Modelling in Natural Resource Management: A Comparison of Four Case Studies. Integrated Assessment, 4(2), 62-72.

Henderson, J.C. and Schilling, D.A. (1985). Design and Implementation of Decision Support Systems in the Public Sector. MIS Quarterly, 9(2), 157-169.

James, H. and Barnes, J. (1984). Cognitive Biases and Their Impact on Strategic Planning. Strategic Management Journal, 5, 129-137.

Jones, N.A., Perez, P., Measham, T.G., Kelly, G.J., d'Auquino, P., Daniell, K.A., Dray, A. and Ferrand, N. (2009). Evaluating participatory modeling: developing a framework for cross-case analysis. Environmental Management, 44, 1180-1195.

Lempert, R.J., Popper, S.W. and Bankes, S.C. (2003). Shaping the Next One Hundred Years: New Methods for Quantitative, Long-Term Policy Analysis, RAND.

McGrail, S., Halamish, E., Teh-White, K. and Clark, M. (2013). Diagnosing and anticipating social issue maturation: Introducing a new diagnostic framework. Futures, 46, 50-61.

Pahl-Wostl, C. and Hare, M. (2004). Processes of social learning in integrated resources management. Journal of Community \& Applied Social Psychology, 14(3), 193-206.

Schoemaker, P.J.H. (1993). Multile Scenario Development: Its Conceptual and behavioral Foundation. Strategic Management Journal, 14, 193-213.

Schwenk, C.R. (1984). Cognitive simplification processes in strategic decision-making. Strategic Management Journal, 5(2), 111-128.

Silver, D., Weitzman, B. and Brecher, C. (2002). Setting an Agenda for Local Action: The Limits of Expert Opinion and Community Voice. Policy Studies Journal, 30(3), 362-378.

Sondeijker, S. (2009). Imagining Sustainability: methodological building blocks for transition scenarios, Rotterdam: Erasmus University Rotterdam.

Störmer, E., Truffer, B., Dominguez, D., Gujer, W., Herlyn, A., Hiessl, H., Kastenholz, H., Klinke, A., Markard, J., Maurer, M. and Ruef, A. (2009). The exploratory analysis of trade-offs in strategic planning: Lessons from Regional Infrastructure Foresight. Technological Forecasting and Social Change, 76(9), 1150-1162.

Tonn, B., English, M. and Travis, C. (2000). A Framework for Understanding and Improving Environmental Decision Making. Journal of Environmental Planning and Management, 43(2), 163-183.

Tversky, A. and Kahneman, D. (1974). Judgment under Uncertainty: Heuristics and Biases. Science, 185(4157), 1124-31.

United Nations. Economic and Social Commission for Asia and the Pacific. (2004). Guidelines on Strategic Planning and Management of Water Resources, New York: United Nations.

Varum, C.A. and Melo, C. (2010). Directions in scenario planning literature - A review of the past decades. Futures, 42(4), 355-369.

Walker, W.E. (2000). Policy Analysis: A Systematic Approach to Supporting Policymaking in the Public Sector. Journal of Multi-Criteria Decision Analysis, 9, 11-27.

Wheeland, C.M. (2003). Implementing A Community-Wide Strategic Plan: Rock Hill's Empowering the Vision 10 Years Later. The American Review of Public Administration, 33(1), 46-69.

Wiek, A., Binder, C. and Scholz, R.W. (2006). Functions of scenarios in transition processes. Futures, 38(7), 740-766.

Wright, G. and Goodwin, P. (2009). Decision making and planning under low levels of predictability: Enhancing the scenario method. International Journal of Forecasting, 25, 813-825. 